\title{
Pax3 activation promotes the differentiation of mesenchymal stem cells toward the myogenic lineage
}

\author{
Eun Ji Gang, Darko Bosnakouski, Tugba Simsek, Khai To, Rita C.R. Perlingeiro*
}

Department of Developmental Biology, University of Texas Southwestern Medical Center, 5323 Harry Hines Blvd., Dallas, Texas 75390-9133, Texas, USA

\section{A R T I C L E I N F O R M A T I O N}

Article Chronology:

Received 6 September 2007

Revised version received

29 January 2008

Accepted 20 February 2008

Available online 5 March 2008

Keywords:

Mesenchymal stem cells

Pax3

Cell differentiation

Muscle

Fat

Bone

Cartilage

\begin{abstract}
A B S T R A C T
Mesenchymal stem cells (MSCs) residing within the bone marrow (BM) differentiate into multiple lineages, including fat, bone, and cartilage. Because MSCs are multipotent and have a great capacity to be expanded in vitro, these cells are an attractive candidate for clinical applications to repair or regenerate damaged tissues of mesenchymal origin. However, application of MSCs to muscle degenerative diseases has been hampered by the poor differentiation of MSCs into the muscle lineage. To date most methods require the presence of strong non-physiological agents, such as azacytidine. In the present study we explored the potential of Pax3, the master regulator of the embryonic myogenic program, to promote myogenic differentiation from MSCs. Our results clearly demonstrate that Pax3 promotes the differentiation of MSCs towards the myogenic lineage, which occurs at the expense of other mesenchymal lineages including fat, bone, and cartilage. This effect is cell typeselective since Pax3 overexpression in endothelial cells fails to promote myogenesis. These results highlight the potential of regulating transcriptional pathways to direct differentiation of adult stem cells.
\end{abstract}

(C) 2008 Elsevier Inc. All rights reserved.

\section{Introduction}

In the last decade, a number of studies have pointed to the existence of cells within the bone marrow (BM) endowed with muscle regenerative potential [1-6]. Initial studies by Ferrari et al. [1] demonstrated that BM cells were capable of migrating from circulation and participate in the regeneration process of damaged muscle fibers in cardiotoxin-injured immunodeficient mice. This finding was followed by a number of reports documenting engraftment after $\mathrm{BM}$ transplantation into dystrophic mice [2-4,7]. Although these results were encouraging, overall the levels of engraftment were low with less than $1 \%$ of total muscle fibers being donor-derived [2,7], and thus unlikely to provide functional benefit. Since the studies described above have involved the transplantation of both whole BM [7], which contains a heterogeneous cell population, or highly purified hematopoietic stem cells (BM SP cells) [2], one could hypothesize that such low engraftment was due to the use of a cell population with limited muscle potential.

Mesenchymal stem cells (MSCs), which reside within the stromal compartment of adult BM, have been identified as a non-hematopoietic stem cell population capable of selfrenewal and multi-lineage differentiation into mesenchymal lineages, including bone, fat, cartilage, and connective tissue [8-10]. Although less than $0.01 \%$ of the BM mononuclear cell fraction comprises MSCs [10], their easy isolation, rapid expansion and multi-lineage differentiation draw attention to their therapeutic potential in regenerative medicine and tissue

\footnotetext{
* Corresponding author. Fax: +1 2146481960.

E-mail address: rita.perlingeiro@utsouthwestern.edu (R.C.R. Perlingeiro).
} 
engineering. Unlike other mesenchymal lineages (such as adipocytes or osteoblasts), skeletal myoblasts have not been easily differentiated from MSCs. Initial induction protocols to differentiate MSCs into myogenic progenitors have employed 5-azacytidine [11], a strong demethylating agent associated with muscle gene activation, in particular MyoD [12-14]. The drawback of this non-physiological method is excessive cell death, which results in virtually none [15] or very few surviving cells that are then endowed with myogenic features (not shown). A more reasonable approach consists of culturing MSCs with myoblasts [16] or myoblast-conditioned medium [15]. Recently, galectin-1 has been identified as a soluble factor present in myoblast-conditioned medium, that has the capacity to promote myogenic conversion of dermal fibroblasts [17] and fetal MSCs [15]. This conversion seems to occur via activation of the myogenic regulatory factors (MRFs), including Myf-5, MyoD, and myogenin [15], as observed during embryonic myogenesis [18-20]. Another reported approach [21] made use of activated Notch to generate skeletal muscle cells from human MSCs. Although the results were somewhat encouraging, the rationale for using Notch1 was not made clear.

During embryogenesis, all skeletal muscles, except for those of the head are derived from transient condensations of paraxial mesoderm, the somites, located next to the neural tube and notochord [22]. Signals from these structures lead to patterning of the somite to form the sclerotome, a precursor for the skeleton, and the dermomyotome, the precursor for both dermis and muscle [22,23]. Cells expressing the transcription factor Pax3 within the dermomyotome migrate medially through the dorsomedial lip of the dermomyotome to form an epithelial sheet, known as the myotome [24]. At this site myogenesis occurs $[25,26]$ upon activation of MRFs, including Myf-5, Mrf4, MyoD, and myogenin. Since the role of Pax3 upstream of MRFs is essential for embryonic muscle specification $[18,19,24,27-30]$, we investigated the potential of Pax3 to drive myogenesis from a murine MSC as well as its effects on other mesenchymal lineages.

\section{Materials and methods}

\section{Cell lines and culture conditions}

MSCB9, a murine mesenchymal stem cell line generated in our laboratory as previously described [31] was used for the experiments. These cells were maintained in MSC expansion medium consisting of low-glucose Dulbecco's modified Eagle's medium (LG-DMEM; Invitrogen) supplemented with 40\% Molecular Cell Developmental Biology (MCDB)-201 medium (Sigma), 10\% fetal bovine serum (FBS, Invitrogen), $1 \times$ insulin-transferrin-selenium (ITS; Sigma), 1× linoleic-acid-bovine serum-albumin (Sigma), $10^{-8} \mathrm{M}$ dexamethasone (Sigma), $10^{-4} \mathrm{M}$ ascorbic acid 2-phosphate (Sigma), $50 \mathrm{U} / \mathrm{ml}$ penicillin/streptomycin (Invitrogen) and the following growth factors: $10 \mathrm{ng} / \mathrm{ml}$ of recombinant human platelet-derived growth factor-BB (hPDGF-BB; R\&D Systems), $10 \mathrm{ng} / \mathrm{ml}$ of recombinant murine epidermal growth factor (mEGF; Sigma), and $1000 \mathrm{U} / \mathrm{ml}$ of recombinant murine leukemia inhibitory factor (LIF, Chemicon). BEND3, a mouse endothelial cell line (generously provided by Dr. R. Brekken, UT Southwestern Medical Center), and NIH 3T3 fibroblasts were main- tained in LG-DMEM supplemented with 10\% FBS, 2 mM Lglutamine (Invitrogen) and antibiotics. Medium was changed twice a week. For sub-culture, cells were trypsinized with $0.25 \%$ Trypsin-EDTA (Invitrogen) and replated at a subcultivation ratio of 1:3. C2C12 cells [32] were used as positive control for gene expression analyses. Terminal differentiation was induced by plating C2C12 cells at $8 \times 10^{4}$ cells per $\mathrm{cm}^{2}$ on gelatinized dishes in $2 \%$ horse serum (HS) (Atlanta Biologicals) for 4 days.

\section{Retroviral infection and purification of $\mathrm{GFP}^{+}$cells}

MSCV-Pax3iresGFP was created by sub-cloning the cDNA for Pax3 obtained from pSPORT-Pax3 (Open Biosystems) into pMSCViresGFP as an EcoR I/Xho I fragment. MSCV-Pax3iresGFP or MSCViresGFP (control vector) were transfected into 293T cells using FuGENE6 Transfection Reagent (Roche Diagnostics) as recommended by the manufacturer. Virus-containing supernatant was collected $48 \mathrm{~h}$ after transfection and filtered through $0.45 \mu \mathrm{m}$ filter before use. Approximately $4 \times 10^{5}$ MSCB9 cells were suspended in $5 \mathrm{ml}$ of viral supernatant containing $10 \mathrm{ng} / \mathrm{ml} \mathrm{hPDGF-BB}, 10 \mathrm{ng} / \mathrm{ml} \mathrm{mEGF}, 1000 \mathrm{U} / \mathrm{ml} \mathrm{mLIF}$ and $8 \mu \mathrm{g} /$ $\mathrm{ml}$ hexadimethrin bromide (polybrene; Sigma). Cells were then transferred to 6-well plates and centrifuged at $2500 \mathrm{rpm}$ for $90 \mathrm{~min}$ at $33{ }^{\circ} \mathrm{C}$ on a Hettich centrifuge. After an overnight incubation at $37{ }^{\circ} \mathrm{C}$ with $5 \% \mathrm{CO}_{2}$ in air, supernatant was removed and changed with fresh MSC expansion medium

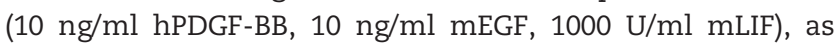
described above. A similar approach was used for BEND3 and NIH3T3 cells, except for the culture medium which consisted of LG-DMEM supplemented with 10\% FBS. Two days following infection, cells were harvested and analyzed on a FACS Aria (Becton-Dickinson) for GFP expression. Propidium iodide $(1 \mu \mathrm{g} /$ $\mathrm{ml}$; Pharmingen) was used to exclude dead cells. For purification, infected cells were sorted based on the gating of $\mathrm{GFP}^{+}$on the fluorescein isothiocyanate (FITC) channel.

\section{Induction of multi-lineage differentiation in vitro}

For myogenic differentiation, cells were cultured for up to 3 weeks in several muscle induction conditions as follows: LGDMEM supplemented with $10 \%$ fetal bovine serum, MSC expansion medium containing no growth factors, LG-DMEM supplemented with a mixture of $5 \%$ horse serum (HS) and $10 \%$ fetal bovine serum, and LG-DMEM supplemented with $5 \%$ or $2 \%$ horse serum. Multinucleated myotubes were observed under phase contrast microscope (Olympus). For adipogenic differentiation, cells were plated in the presence of Minimum Essential Medium (MEM) Alpha medium containing horse serum (12.5\%), fetal bovine serum (12.5\%), penicillin/streptomycin (50 U/ml), 2-mercaptoethanol $\left(10^{-4} \mathrm{M}\right.$; Sigma), and hydrocortisone $\left(10^{-4} \mathrm{M}\right.$; StemCell Technologies). Formation of lipid vacuoles in the cells was visualized by Oil Red O staining. For osteogenic differentiation, cells were cultured in the presence of DMEM medium with fetal bovine serum (10\%), penicillin/streptomycin $(50 \mathrm{U} / \mathrm{ml})$, ascorbic acid 2-phosphate (50 $\mu \mathrm{mol} / \mathrm{l})$, dexamethasone $(0.1 \mu \mathrm{mol} / \mathrm{l})$, and $\beta$-glycerolphosphate (10 mmol/l; Sigma). Characterization was performed by Alizarin Red S staining, which detects calcium deposition. For chondrogenesis, cells were cultured as pellets at a density of $3 \times 10^{5}$ cells $/ \mathrm{ml}$ in serum free-chemically defined medium 
consisting of DMEM (high-glucose), 1x insulin-transferrinselenium, 1× linoleic-acid-bovine serum-albumin, ascorbic acid 2-phosphate $(50 \mu \mathrm{g} / \mathrm{ml})$, dexamethasone $(100 \mathrm{nM})$ and $10 \mathrm{ng} / \mathrm{ml}$ hTGF $\beta 1$ (R\&D Systems). Medium was changed every two days. Paraffin-embedded pellet cultures were fixed with $10 \%$ formalin, dehydrated and cut into $5 \mu \mathrm{m}$-thick sections. Alcian Blue staining was used to detect cartilage formation.

\section{Reverse transcriptase polymerase chain reaction (RT-PCR) Analysis}

Total RNA was isolated using Trizol (Invitrogen) as recommended by the manufacturer. First strand cDNA was produced using Superscript II reverse transcriptase (Invitrogen) with Oligo dT. $5 \%$ of first strand reaction was used for each ensuing PCR reaction. Primer sequences and PCR conditions are described in Table 1. For real time PCR, all probe sets were acquired from Applied Biosystems.

\section{Immunofluorescence staining of cultured cells}

Briefly, cells on coverslips were fixed in $4 \%$ paraformaldehyde/ PBS and permeabilized with $0.3 \%$ Triton X-100 (Sigma) for $15 \mathrm{~min}$ at room temperature. Cells were then incubated overnight at $4^{\circ} \mathrm{C}$ with primary antibodies including Pax3 (R\&D systems), MyoD (BD Biosciences), myogenin (BD Biosciences), and MHC (Developmental Studies Hybridoma Bank). A Cy3
(Jackson Immunoresearch Laboratories) secondary antibody was used. DAPI (4,6-diamidino-2-phenylindole; Fluka) was used to counter-stain nuclei. Fusion index was defined as the percentage of nuclei belonging to MHC-positive cells with three or more nuclei. Isotype control antibodies were used as negative control staining. Immunofluorescent signals were captured and analyzed using a fluorescence microscope (Olympus) and MetaVue5.0 software.

\section{Western blot}

Western blots were performed using the following antibodies: mouse anti-MyoD (BD Biosciences), mouse monoclonal antiPax3 (R\&D Systems), and mouse monoclonal anti-actin (Sigma).

\section{Results}

Pax3 directs MSCB9 cells toward the myogenic lineage

To evaluate the effect of Pax3 on the differentiation of MSCs into the myogenic lineage, we transduced Pax3 into the mesenchymal stem cell line MSCB9 [31]. One week after retroviral infection, MSCB9-Pax3 cultures contained cells with elongated morphology (Fig. 1A, left panel), which was not observed in control vector-transduced MSCB9 cells (MSCB9-Vector) (Fig. 1A, right panel). To obtain a homogeneous population of Pax3-

Table 1 - Mouse primer sequences information for reverse transcription-PCR

\begin{tabular}{|c|c|c|c|}
\hline Gene & Primer pair sequence & Annealing temperature $\left({ }^{\circ} \mathrm{C}\right)$ & Product size (bp) \\
\hline \multirow[t]{2}{*}{$\beta$-actin } & GTGGGGCGCCCCAGGCACCA & 50 & 520 \\
\hline & СTCСTTAATGTCACGCACGATTTC & & \\
\hline \multirow[t]{2}{*}{ MGB } & ACCATGGGGCTCAGTGATGGGGAG & 55 & 318 \\
\hline & CAGGTACTTGACCGGGATCTTGTGC & & \\
\hline \multirow[t]{2}{*}{ MyoD } & GACAGGACAGGACAGGGAGG & 50 & 359 \\
\hline & GCACCGCAGTAGAGAAGTGT & & \\
\hline \multirow[t]{2}{*}{ Myf5 } & TGAATGTAACAGCCCTGTCTGGTC & 50 & 256 \\
\hline & CGTGATAGATAAGTCTGGAGCTGG & & \\
\hline \multirow[t]{2}{*}{ MRF4 } & CTGAAGACTGCTGGAGGC & 50 & 235 \\
\hline & CTACATTGAGCGTCTACA & & \\
\hline \multirow[t]{2}{*}{ Myogenin } & AGAGGAAGTCTGTGTCGGTG & 50 & 177 \\
\hline & GTAGGCGCTCAATGTACTGG & & \\
\hline \multirow[t]{2}{*}{$\operatorname{PPAR} \gamma-2$} & GGAGATTCTCCTGTTGACCCAG & 65 & 403 \\
\hline & GGCACTCAATGGCCATGAG & & \\
\hline \multirow[t]{2}{*}{ LPL } & TTAACTACCCCCTAGACAACGTCCA & 50 & 388 \\
\hline & AAGAGATGAATGGAGCGCTCG & & \\
\hline \multirow[t]{2}{*}{ Adipsin } & AGACCCCTACCCTTGCAATACG & 50 & 376 \\
\hline & TGTTACCATTTGTGATGTTTTCGATC & & \\
\hline \multirow[t]{2}{*}{ OPN } & TGGAGATCGAATTCTGCTTG & 50 & 720 \\
\hline & TCAAGTGCTTGAGGGCATAC & & \\
\hline \multirow[t]{2}{*}{ Cbfa-1 } & AGTAGCCAGGTTCAACGATCTGA & 50 & 137 \\
\hline & GGACCGTCCACTGTCACTTTAATA & & \\
\hline \multirow[t]{2}{*}{ Coll II } & GGCAACAGCAGGTTCACATA & 55 & 166 \\
\hline & CСАСАССАAАTTCСТGTTCA & & \\
\hline \multirow[t]{2}{*}{ Agg } & CTAAGTTCCAGGGTCACTGTTACCG & 59 & 270 \\
\hline & TCCTCTCCGGTGGCAAAGAAGTTG & & \\
\hline \multirow[t]{2}{*}{ Coll X } & AAGGAGTGCCTGGACACAAT & 55 & 461 \\
\hline & GTCGTAATGCTGCTGCCTAT & & \\
\hline
\end{tabular}

MGB, myoglobin; MRF4, myogenic regulatory factor 4; PPAR- $\gamma$ 2, peroxisome proliferator-activated receptor gamma 2; C/EBP- $\alpha$, CCAAT/enhancerbinding protein-alpha; LPL, lipoprotein lipase; OPN, osteopontin; Cbfa-1, core-binding factor-1, Coll II, collagen II; Agg, aggrecan; Coll X, collagen X. 
transduced cells for further characterization, we performed a new retroviral infection and FACS sorted the GFP ${ }^{+}$cells at 2 days post-infection (Fig. 1B, upper panel). Remarkable morphological changes were observed uniquely in MSCB9-Pax3 cultures, in which cells aggregated and formed multinucleated rod-like structures (Fig. 1B, lower left). Consistently, immunofluorescence and gene expression analyses showed that MSCB9-Pax3

A
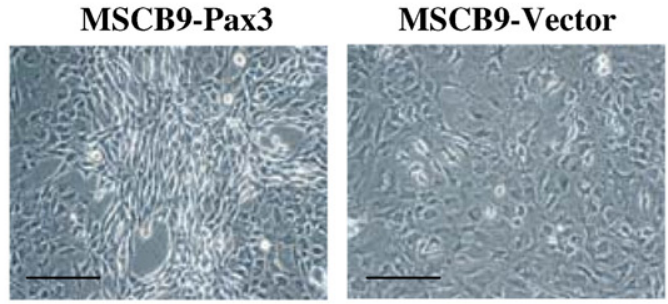

C

i
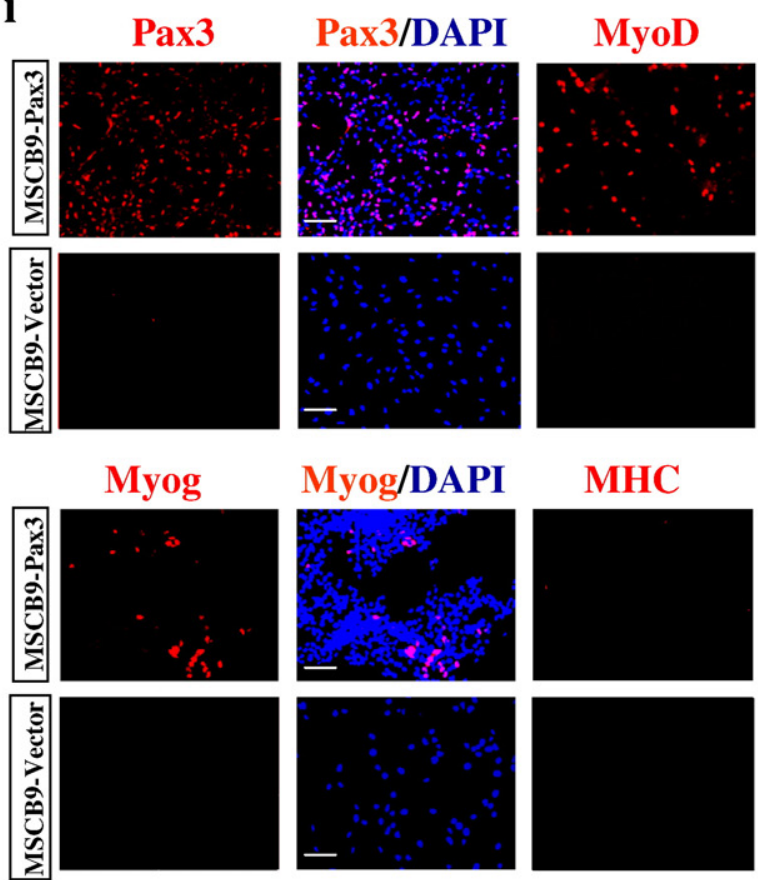

D

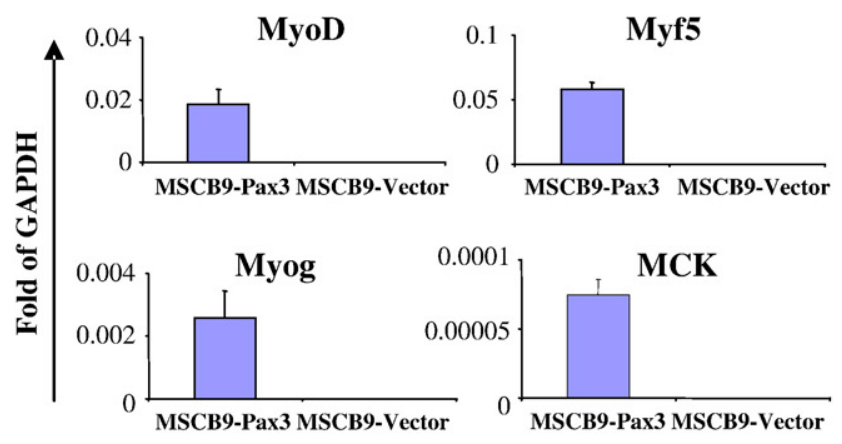

cells expressed Pax3 (Fig. 1C) as well as its downstream myogenic regulatory factors (MRFs) including MyoD, Myf5, and to a lesser extent myogenin (Figs. 1C-D). MHC (myosin heavy chain) and MCK (muscle creatine kinase), markers of terminal muscle differentiation, were not detected (Figs. 1C-D, respectively). Western Blot analyses further corroborate the expression of Pax3 and MyoD in these cells (Fig. 1E). On the other hand,

\section{B}
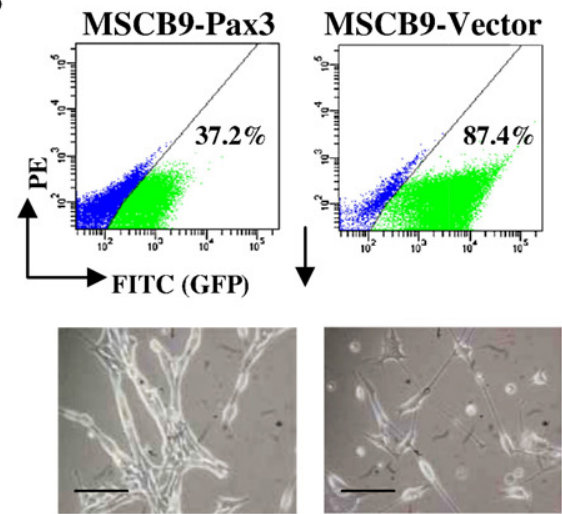

ii

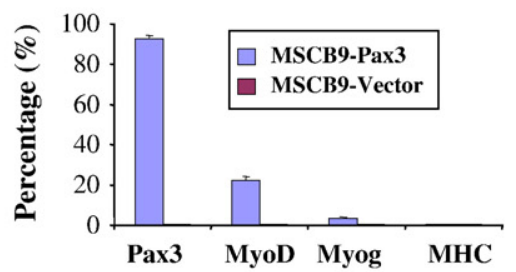

MHC/DAPI
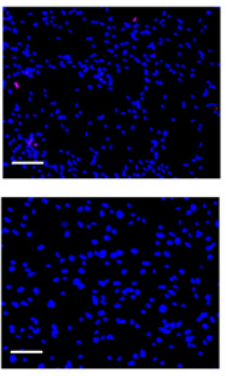

E

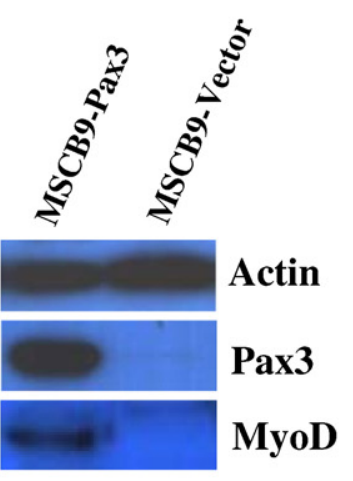


MSCB9-Vector cells did not express Pax3 (Figs. 1C and E) or any of the MRFs (Figs. 1C-E). These data suggest that Pax3 is capable of driving MSCs towards the muscle lineage through activation of MRFs.

MSCB9-Pax3 cells were able to differentiate in vitro into multinucleated myotubes simply by the withdrawal of growth factors from the MSC expansion medium whereas MSCB9Vector cells were not (condition 2; Figs. 2A-B). A similar effect was also observed when cells were cultured in DMEM 10\% FBS (condition 1; Figs. 2 and 3A). Further real time PCR and immunofluorescence analyses of cells growing under this condition (Figs. 3B-E) revealed that while Pax3 expression remains unaffected, an overall up-regulation of the MRFs, MyoD, Myf5, and Myogenin, as well as the terminal differentiation markers, MCK and MHC, are observed in MSCB9-Pax3 cells (Figs. 3B-D) when compared to cultures left to confluence in MSC expansion medium (Figs. 3B-D). Consistent with the morphological observation of myotube formation, fusion index was elevated in MSCB9-Pax3 cells (Fig. 3E). In contrast, MSCB9-Vector cells were negative for all myogenic markers under this muscle differentiation condition (Figs. 3B-D). Taken together, these results suggest that Pax3-transduced MSCs are capable of undergoing terminal muscle differentiation in vitro.

Pax3 blocks adipogenesis, osteogenesis and chondrogenesis of MSCs

Given that MSCB9 cells or MSCB9-Vector cells easily make adipocytes when cultured at a high density (Fig. 4A. ii), the finding of a total absence of fat formation in MSCB9-Pax3 cells under these confluent conditions (Fig. 4A.i) led us to hypothesize that Pax3 might direct MSCs towards the skeletal muscle lineage at the expense of the adipogenic lineage. To investigate whether Pax3 is in fact blocking adipogenesis, we cultured MSCB9-Pax3 cells in adipogenic medium. As expected, the majority of MSCB9-Vector cells differentiated into lipid vacuoles-containing adipocytes which were visualized by Oil Red O staining (Fig. 4A.iv). In contrast, no adipocytes but a few multinucleated myotubes were found in MSCB9-Pax3 cells (Fig. 4A.iii). These results support the hypothesis that Pax3 might prevent the differentiation of MSCs into the adipogenic lineage. The emerging question is whether Pax3 is capable of blocking the other two mesenchymal lineages, specifically osteogenesis and chondrogenesis. To address this question we subjected MSCB9-Pax3 as well as MSCB9-Vector cells to osteogenic and chondrogenic induction medium for up to 4 weeks. Accordingly, MSCB9-Vector control cells differen-
A

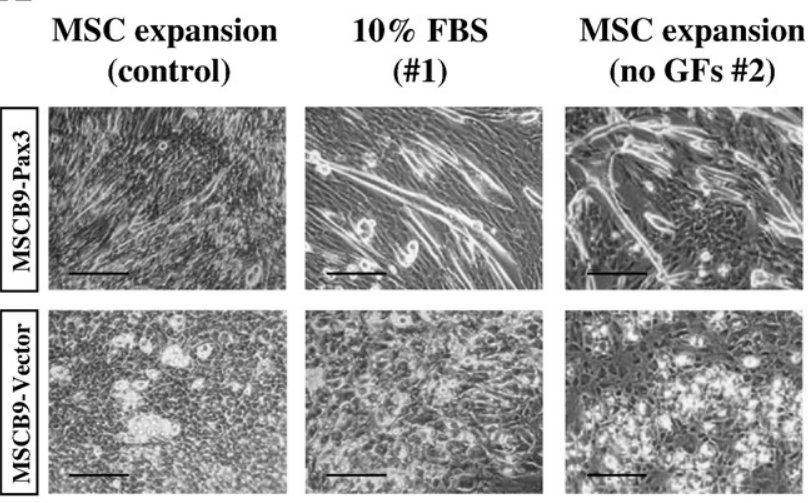

B

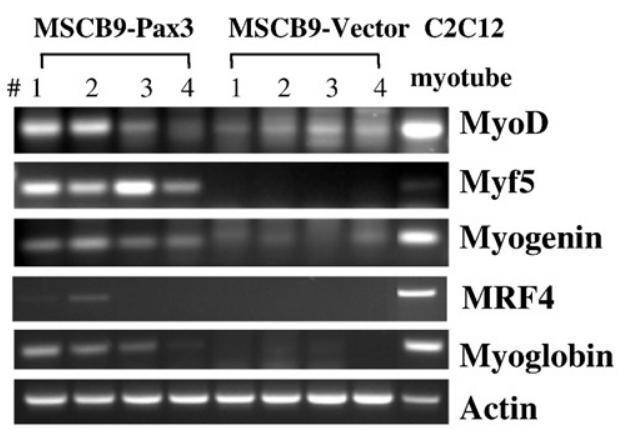

Fig. 2 - Myogenic induction of MSCB9-Pax3 cells.

(A) Morphology of MSCB9-Pax3 and MSCB9-Vector cells growing under expansion (control) and muscle induction (differentiation) conditions for three weeks, and (B) Gene expression analysis for myogenic markers in MSCB9-Pax3 and MSCB9-Vector cells growing under the following culture conditions: \#1 - LG-DMEM containing 10\% FBS; \#2 - MSC expansion medium containing no GFs; \#3 - LG-DMEM supplemented with $5 \%$ HS and $10 \%$ FBS; \#4 - LG-DMEM supplemented with $5 \%$ HS only. Myotubes differentiated from C2C12 cells were used as positive control. Scale bar is $100 \mu \mathrm{m}$.

tiated robustly into osteoblasts and chondrocytes (Fig. 4A.vi and A.viii, respectively) whereas MSCB9-Pax3 cells failed to differentiate into these lineages (Fig. 4A.v and A.vii). These findings were corroborated by gene expression analyses for multi-lineage-specific genes (Fig. 4B). Upon appropriate induction, MSCB9-Vector cells were positive for all the examined

Fig. 1 - Pax3 initiates the myogenic program of MSCs. (A) Morphology of MSCB9-Pax3 and MSCB9-Vector (control) cells growing in monolayer culture in MSC expansion medium. (B) Upper panel: FACS profile for GFP expression in MSCB9-Pax3 and MSCB9-Vector cells two days after retroviral infection. Channel detecting GFP is indicated on $x$ axis, and autofluorescence on $y$ axis. GFP ${ }^{+}$cells were sorted according to represented gates and cultured in MSC expansion medium. Lower panel: Morphology of these cells 2 days post-sorting. (C) (i) Immunofluorescent staining of MSCB9-Pax3 and MSCB9-Vector cells: Pax3, MyoD, Myogenin, and MHC in red (Cy3); Cells are co-stained with DAPI (blue); and (ii) Graph representing the percentage of cells expressing these myogenic markers. Data are mean $>300$ cells). (D) Gene expression analysis for myogenic markers in MSCB9-Pax3 and MSCB9-Vector cells. RNA was isolated from these cells and analyzed for the expression of specific myogenic markers by real time RT-PCR, in which transcripts were normalized to GAPDH. Error bars indicate standard deviation from 3 independent experiments. (E) Western blot analysis for Pax3 and MyoD expression in MSCB9-Pax3 and MSCB9-Vector cells is shown. Scale bar is $100 \mu \mathrm{m}(\mathrm{A}-\mathrm{C})$. 

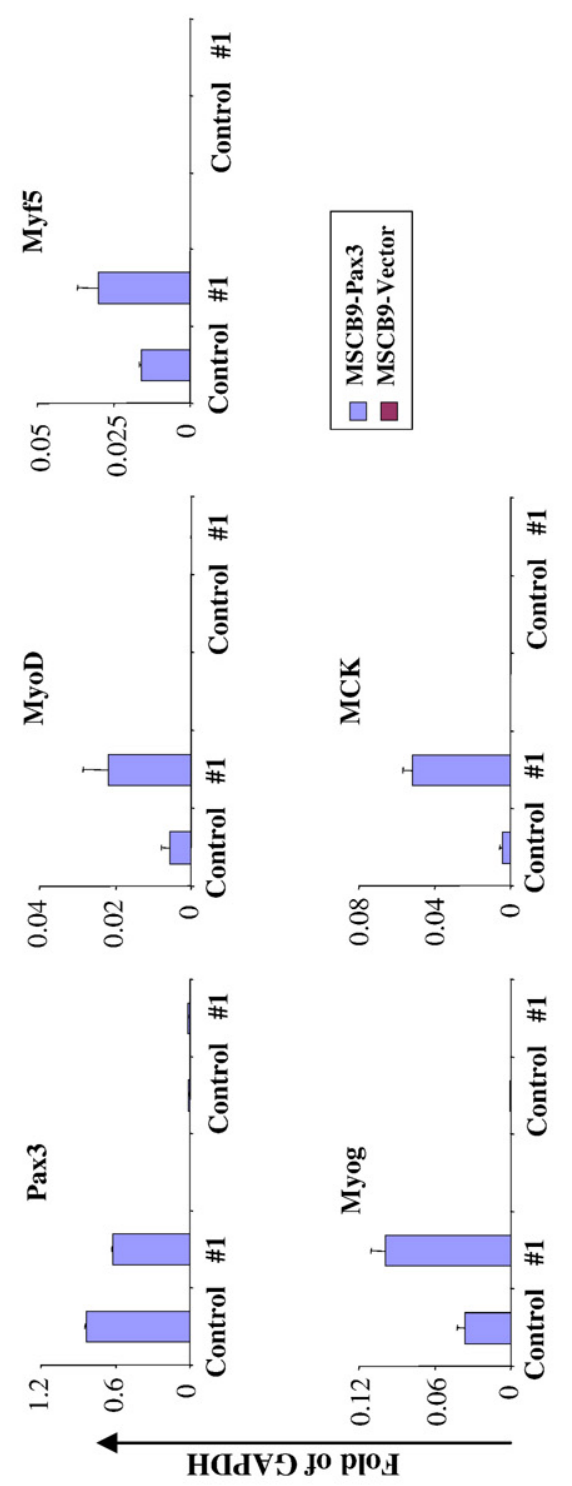

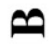

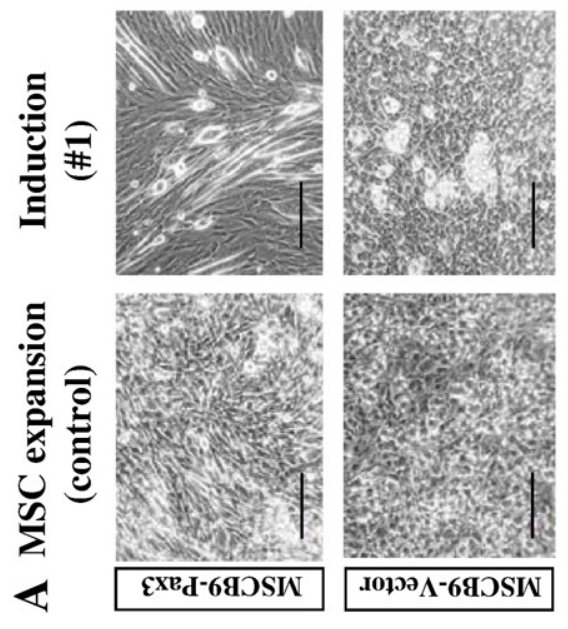

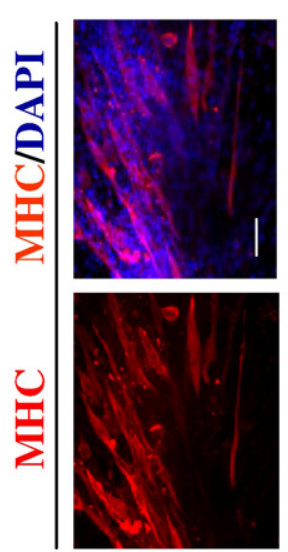
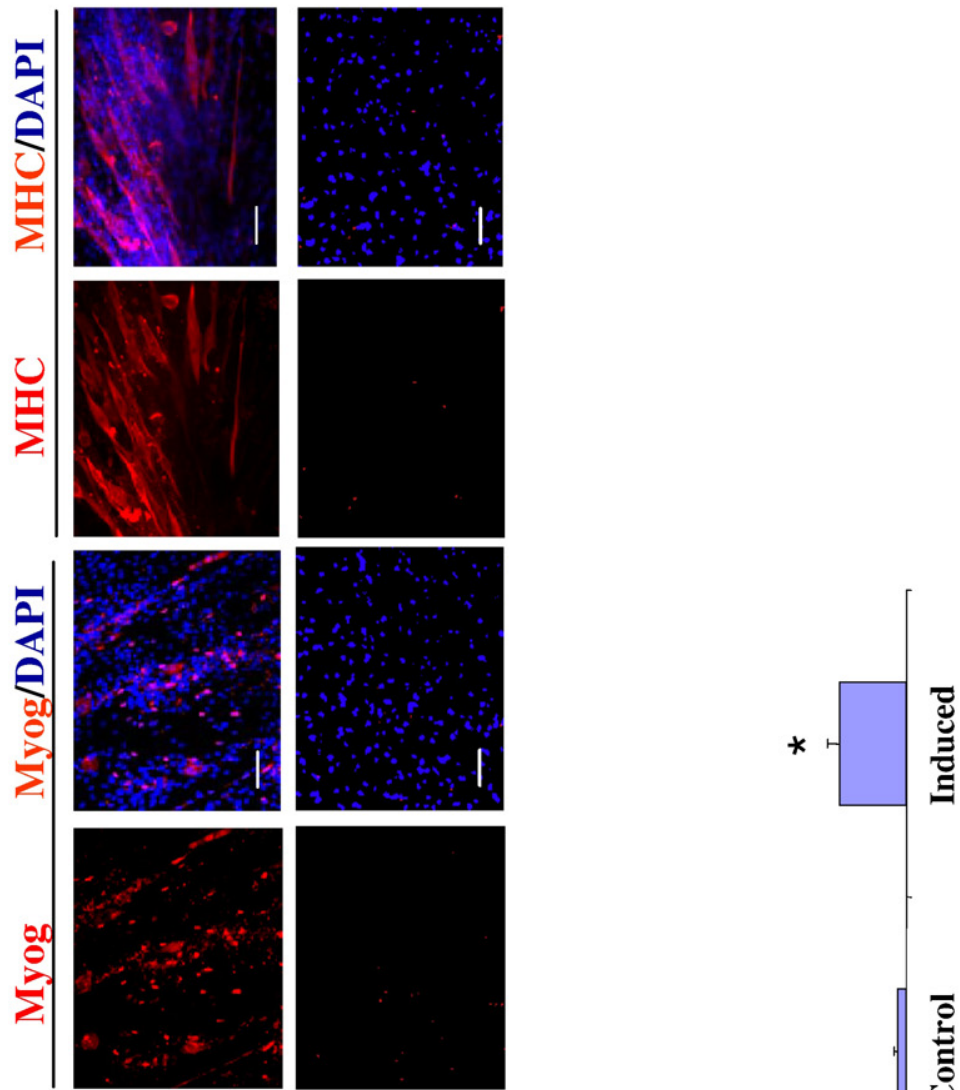

\&. 8 के

(\%) хәрu! uo!sn

따
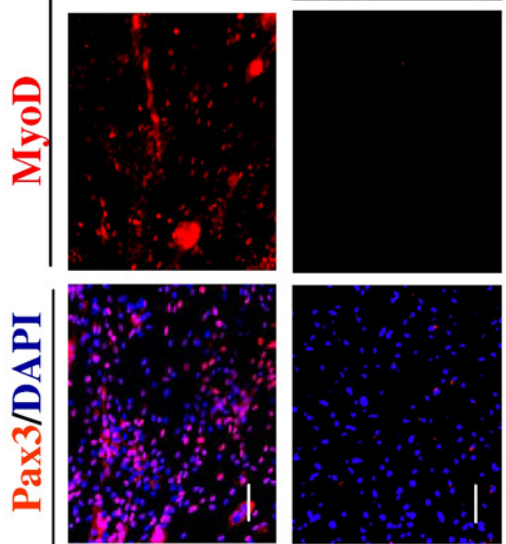

苍
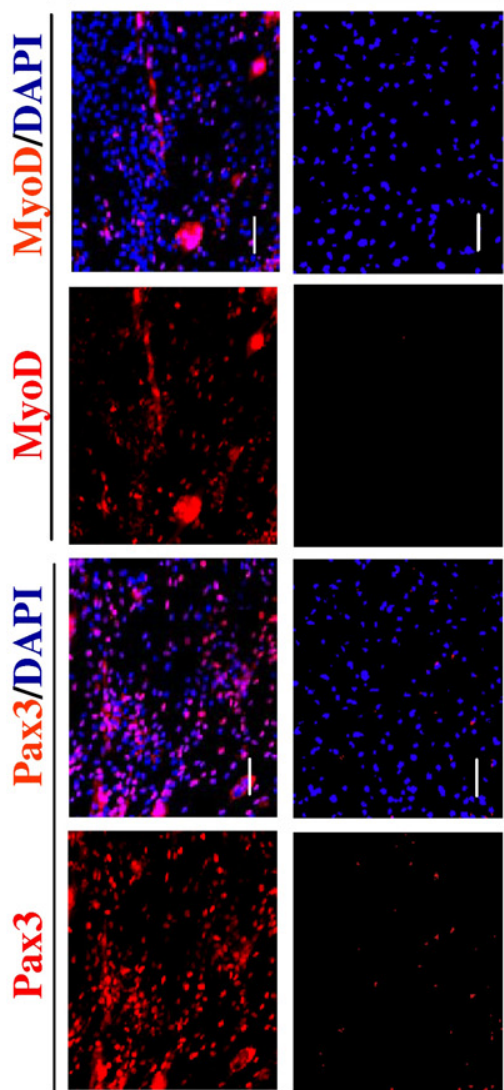

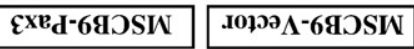

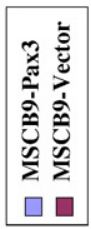
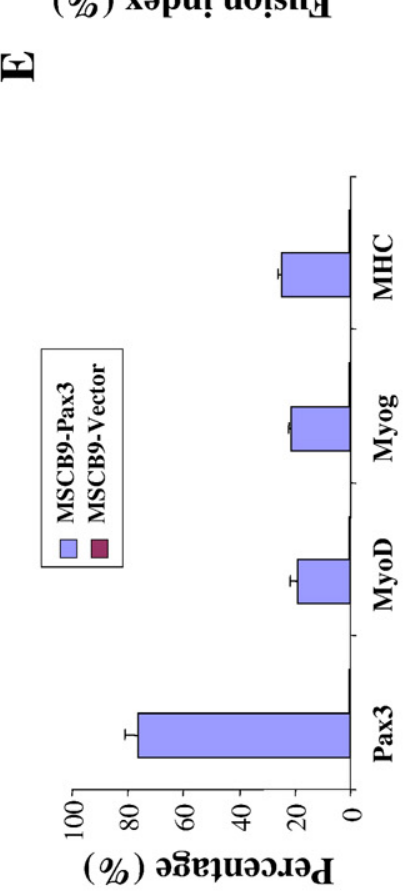

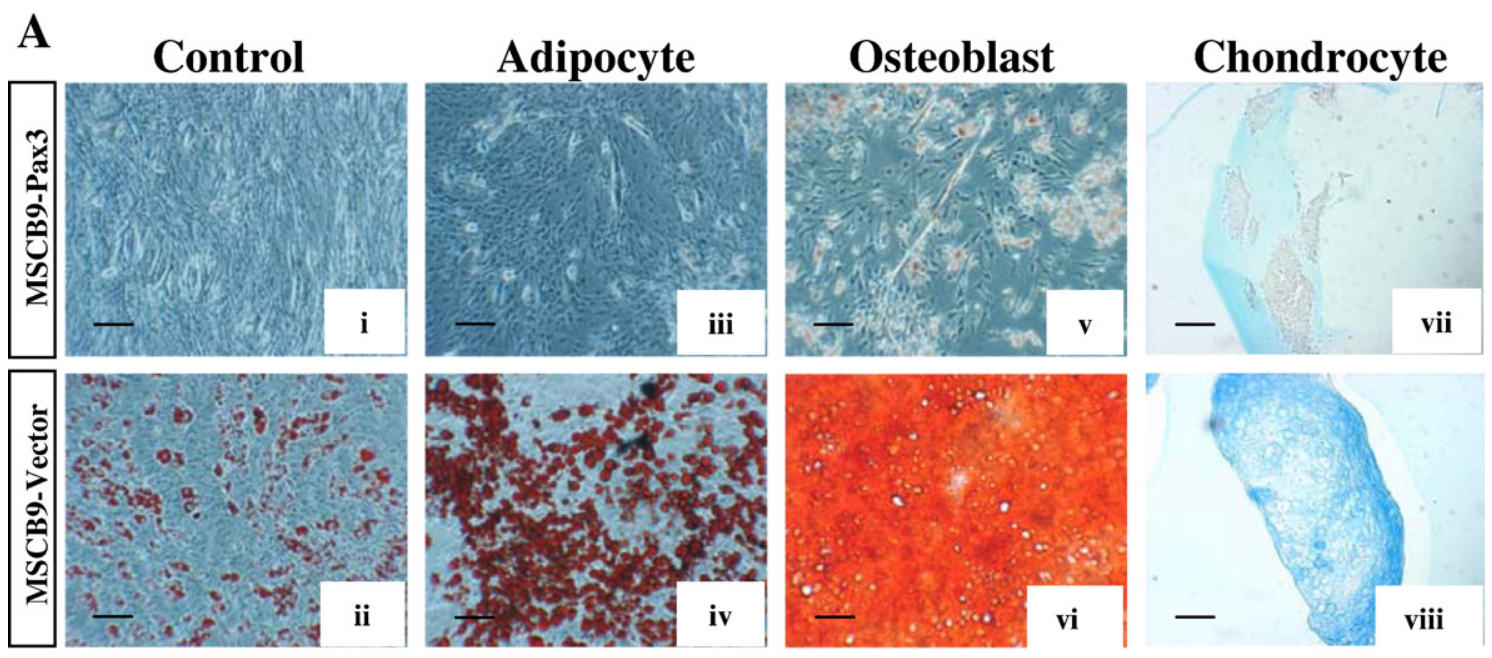

B

Fat

MSCB9-Vec MSCB9-Pax3

D0 D14 D0 D 14

\begin{tabular}{|ll}
\hline$-\infty$ & Adipsin \\
\hline$-\infty$ & LPL \\
\hline$-\infty$ & CEBP- $\alpha$ \\
\hline- & PPAR- $\gamma$ \\
\hline$-\infty$ & Actin
\end{tabular}

Bone

MSCB9-Vec MSCB9-Pax3

D0 D28 D0 D 28

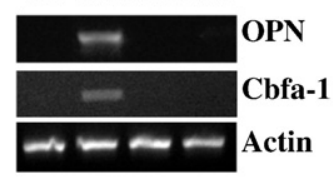

Cartilage

MSCB9-Vec MSCB9-Pax3

D0 D28 D0 D 28

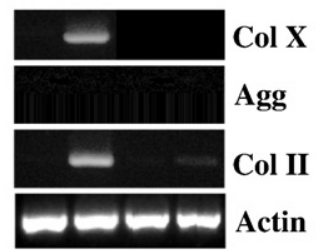

Muscle

MSCB9-Vec MSCB9-Pax3

D0 D21 D 0 D2 1

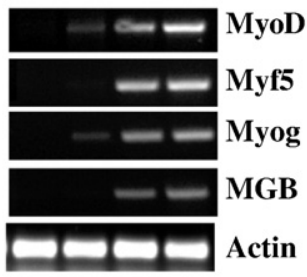

Fig. 4 - Pax3 drives MSCs toward the myogenic lineage at the expense of adipogenic, osteogenic and chondrogenic lineages. (A) Multi-lineage differentiation of MSCB9-Pax3 and MSCB9-Vector cells: Cells were subjected to several conditions as follows, (i,ii) MSC expansion medium at high cell density - MSCB9-Vector cells present lipid vacuoles as evidenced by Oil Red 0 staining; (iii, iv) Adipogenic induction medium - fat formation was characterized by Oil Red O staining; (v,vi) Osteogenic induction medium - bone formation was evidenced by Alizarin Red S, which stains calcium deposition in the extracellular matrix; (vii,viii); Chondrogenic induction medium - cartilage formation was characterized by Alcian Blue staining. Scale bar is $100 \mu \mathrm{m}$. (B) RT-PCR analysis for lineage-specific genes in MSCB9-Vector and MSCB9-Pax3 cells growing under adipogenic, osteogenic, chondrogenic, and muscle induction conditions.

markers for fat, bone and cartilage but not for muscle (Fig. 4B). On the other hand, MSCB9-Pax3 cells expressed only musclespecific genes while markers for other mesenchymal lineages were absent (Fig. 4B). These results suggest that Pax3 drives the commitment of MSCs toward the myogenic lineage at the expense of the adipogenic, osteogenic and chondrogenic lineages.
Can Pax3 drive any cell type towards the muscle lineage?

Since our results show a potent effect of Pax3 in driving the differentiation of MSCs towards the myogenic lineage, we next inquired whether Pax3 could drive other cell types to muscle commitment. For this, we examined the effect of Pax3

Fig. 3 - Characterization of final myogenic differentiation of Pax3-modified MSCs. (A) Morphology of MSCB9-Pax3 and MSCB9-Vector cells growing under expansion (control) and muscle induction (differentiation) conditions for three weeks, and (B) their respective gene expression profile for myogenic markers by real time RT-PCR, in which transcripts were normalized to GAPDH. Error bars indicate standard deviations from two independent experiments performed in duplicate.

(C) Immunofluorescent staining of MSCB9-Pax3 and MSCB9-Vector cells grown under muscle induction condition: Pax3, MyoD, Myogenin, and MHC in red (Cy3); Cells are co-stained with DAPI (blue); (D) Graph representing the percentage of nuclei expressing Pax3, MyoD, or Myogenin, or in a cytoplasm positive for MHC. Data are mean \pm SE. For each cell fraction, 5 representative pictures $(200 x)$ were analyzed and the percentage of positive cells was calculated among total cells ( $>300$ cells). (E) Graph showing the fusion index of MSCB9-Pax3 cells. Cells were stained for MHC (ii) and the fusion index was defined as the percentage of nuclei belonging to MHC-positive cells with three or more nuclei. Data are mean $\pm \mathrm{SE}$. For each cell fraction, 5 representative pictures were analyzed and the percentage of positive cells was calculated among total cells ( $>300$ cells). The number of multinucleated myotubes was significantly increased in the induced group ( $p=0.015$, two tailed t-test).

Differentiation experiments were performed in triplicate. Scale bar is $100 \mu \mathrm{m}$ (A and C). 
A

(i)
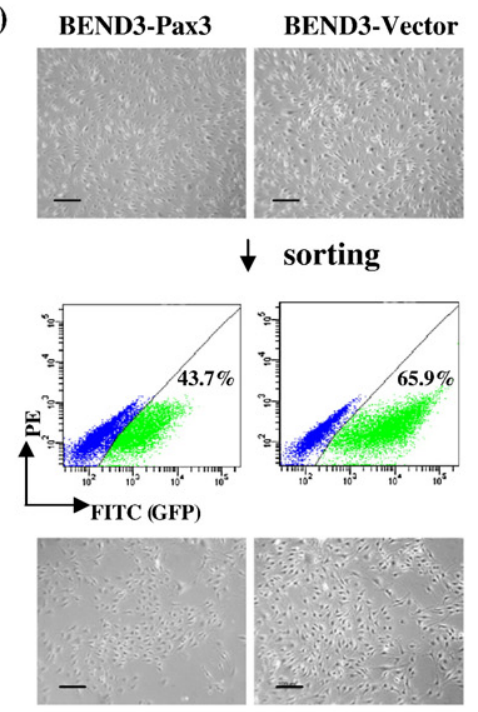

C

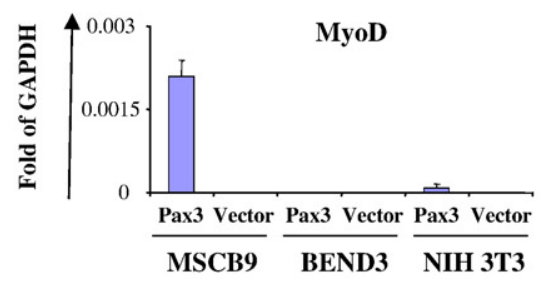

(ii)
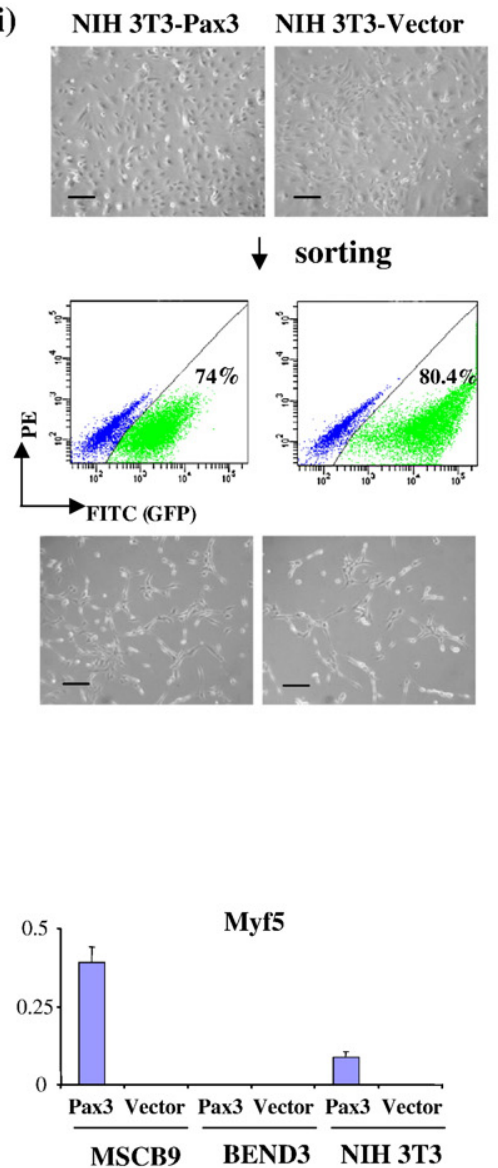

B
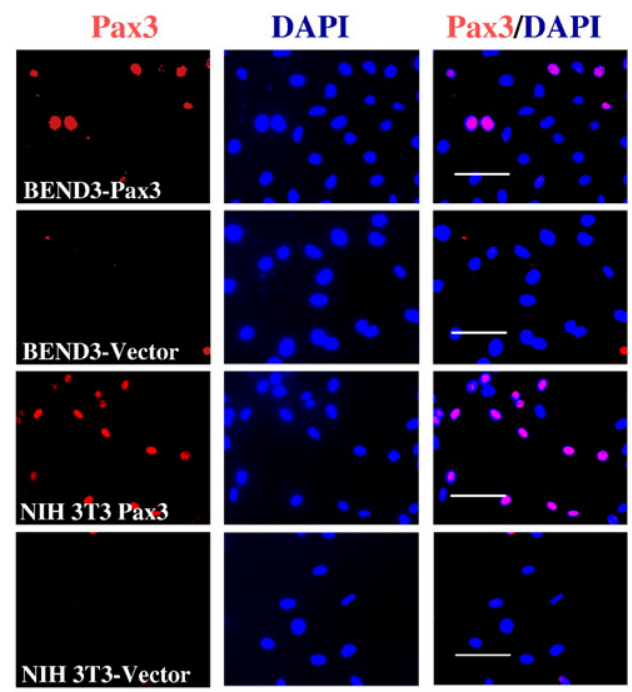

D
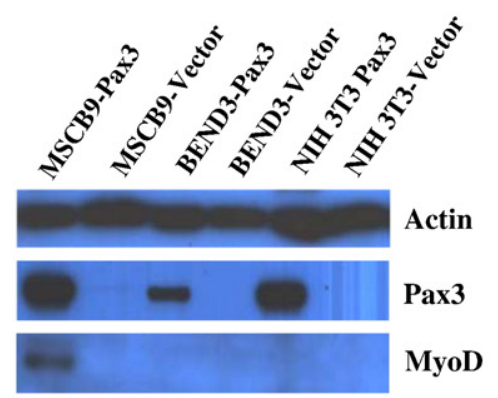

Fig. 5 - Effect of Pax3 overexpression in endothelial and fibroblast cell lines. (A) Upper panel: Morphology of endothelial (BEND3) (i) and fibroblast (NIH 3T3) cells (ii) two days after retroviral infection with MSCV-Pax3iresGFP or control vector MSCViresGFP. Middle panel: FACS profile for GFP expression in BEND3 (i) and NIH 3T3 (ii) cells transduced with Pax3 or control vector two days after retroviral infection. Channel detecting GFP is indicated on $x$ axis, and autofluorescence on $y$ axis. GFP cells were sorted according to represented gates and cultured in MSC expansion medium. Lower panel: Morphology of these cells 2 days after sorting. (B) Immunofluorescent staining shows nuclear expression of Pax3 only in BEND3-Pax3 and NIH 3T3-Pax3 (red) but not in their respective controls (vector). DAPI staining in blue. (C) Relative levels of MyoD, Myf5, Myogenin, and MCK by real time RT-PCR. Transcripts are normalized to GAPDH. Error bars indicate standard deviation from 3 independent experiments. (D) Western blot for Pax3 and MyoD expression in these cell lines. MSCB9 cells were used as reference. Scale bar is $100 \mu \mathrm{m}(\mathrm{A}-\mathrm{B})$.

transduction in a mouse endothelial cell line (BEND3) and in a mouse fibroblast cell line (NIH 3T3). Both cell lines were subjected to retroviral infection with MSCV-Pax3ireGFP or vector control MSCViresGFP, as previously described for MSCB9. No morphological changes were observed two days following infection with either cell line, BEND3 (Fig. 5A.i, upper panel) or NIH 3T3 (Fig. 5A.ii, upper panel), at which point cells were sorted based on GFP expression (Fig. 5A.i-ii, middle panel). Even after this purification step, there were no apparent morphological differences between Pax3-transduced and Vector-transduced cells in BEND3 or NIH 3T3 cell lines (Fig. 5A.i-ii, lower panel). Immunofluorescence staining and western blot analyses confirmed that Pax3 was indeed expressed in Pax3-transduced cells (Fig. 5B and, respectively).

Fig. 6 - Effect of myogenic induction in Pax3-transduced endothelial and fibroblast cell lines. (A) MSCB9 for reference, (B) BEND3 and (C) NIH 3T3 cells were cultured under expansion (control, \#0) or several muscle induction conditions, as follows: \#1, LG-DMEM supplemented with $10 \%$ FBS; \#2, MSC expansion medium containing no growth factors; \#3, LG-DMEM supplemented with $2 \%$ HS. (i) Representative morphology of these cells after three weeks in culture; (ii) Real time RT-PCR analysis of respective cells cultured under the culture conditions described above. cDNA from MSCB9-Pax3 cells was used as positive control. Error bars indicate standard deviations from two independent experiments performed in duplicate. (D) Differentiated cells growing under condition \#2 were analyzed by Western blot for MyoD expression. MSCB9 cells were used as reference. Scale bar is $100 \mu \mathrm{m}$ (A-C). 
We then analyzed the gene expression profile of BEND3-Pax3 and NIH 3T3-Pax3 cells growing in the absence of any muscleinducing agent using MSCB9-Pax3 cells as reference (Fig. 5C). MyoD and Myf5 RNAs were found in MSCB9-Pax3 and NIH 3T3-
Pax3 cells although at much lower levels in the latter (Fig. 5C), and were not present in BEND3-Pax3 cells (Fig. 5C). Myogenin and $\mathrm{MCK}$, markers of terminal skeletal muscle differentiation could be detected in NIH 3T3-Pax3 cells but at insignificant
A

(i)

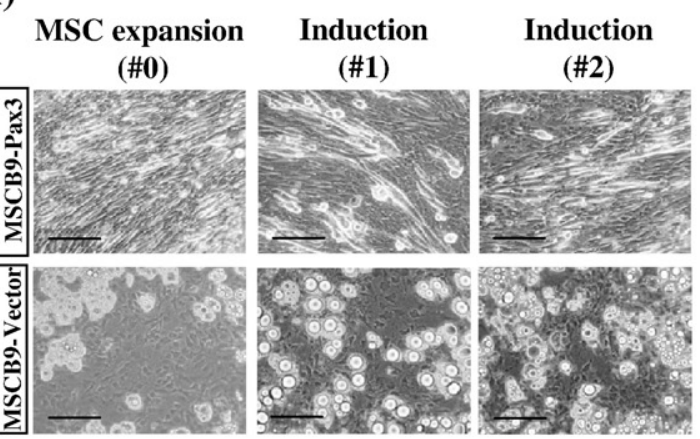

B

(i)

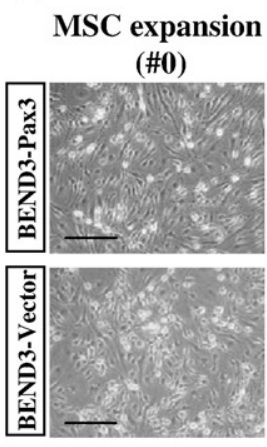

C

(i)

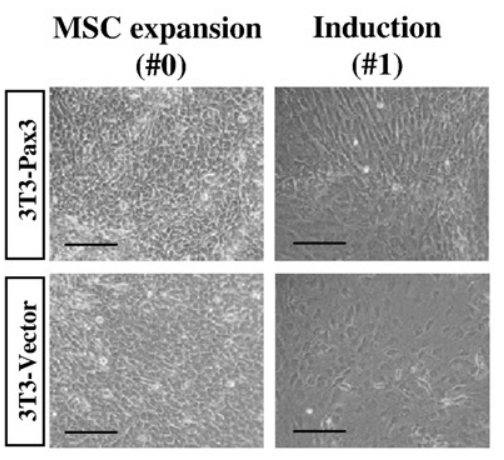

D

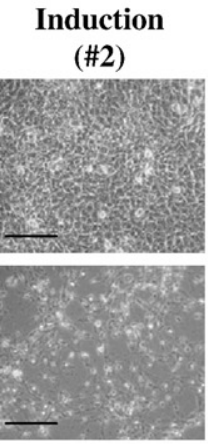

(ii)

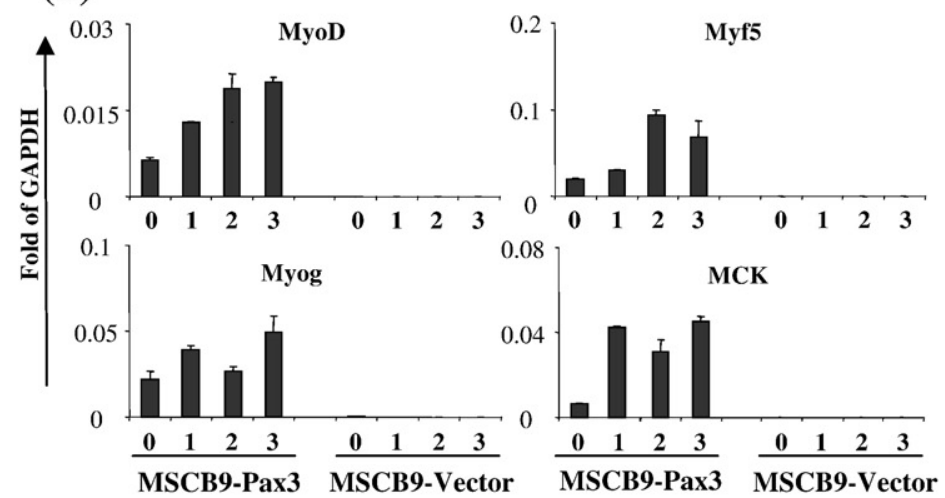

(ii)

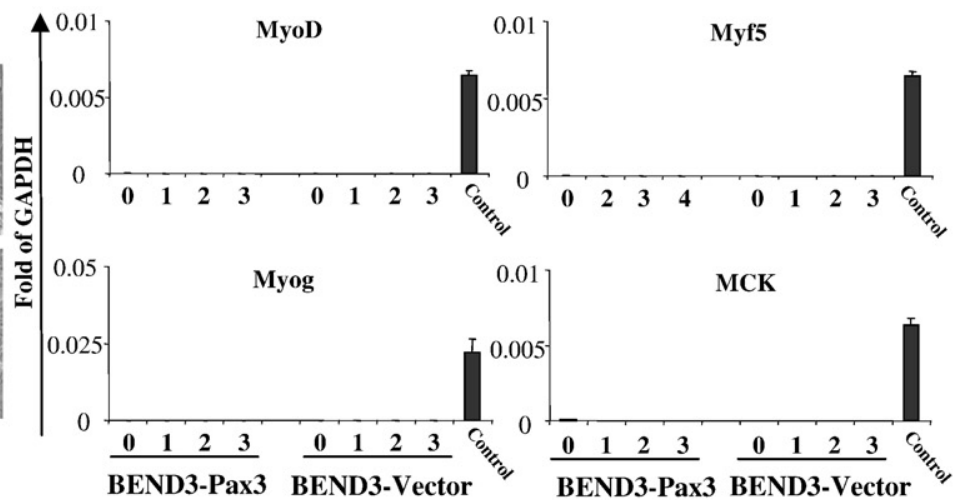

(ii)
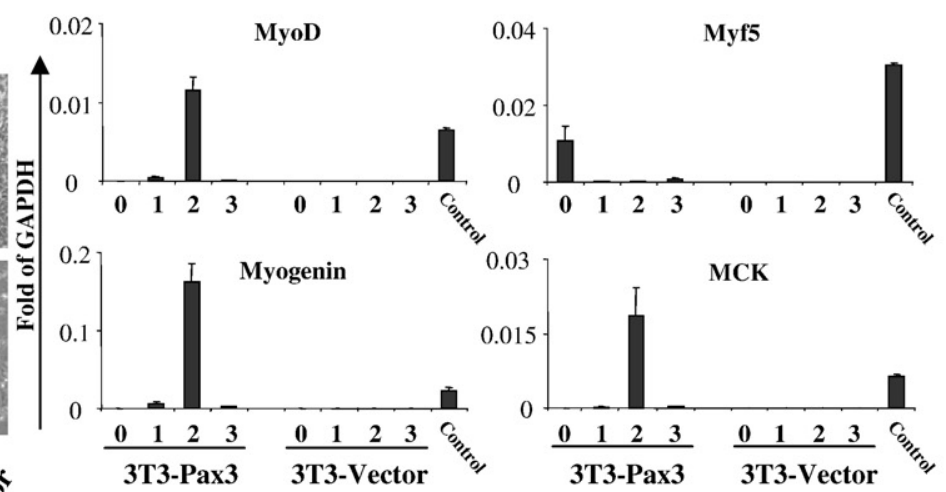

Actin 
levels under this condition (data not shown). At the protein level, MyoD was detectable only in MSCB9-Pax3 cells (Fig. 5D). Thus, despite Pax3 overexpression, BEND3 cells do not seem to have acquired any potential to differentiate towards the muscle lineage while NIH 3T3 cells display limited muscle differentiation potential.
To confirm this assumption, we attempted to induce muscle differentiation of BEND3 and NIH 3T3 cells in vitro by testing several conditions as previously described (Fig. 2B). Muscle differentiation induction of MSCB9-Pax3 and MSCB9Vector cells were used as positive and negative control, respectively (Fig. 6A). Consistently with our previous results,
A

$$
\begin{array}{lll}
1 & 2 & 3
\end{array}
$$

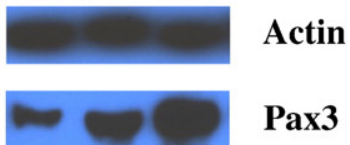

1. BEND3-Pax $31^{\circ}$ infection

2. BEND3-Pax $32^{\circ}$ infection

3. MSCB9-Pax3

B
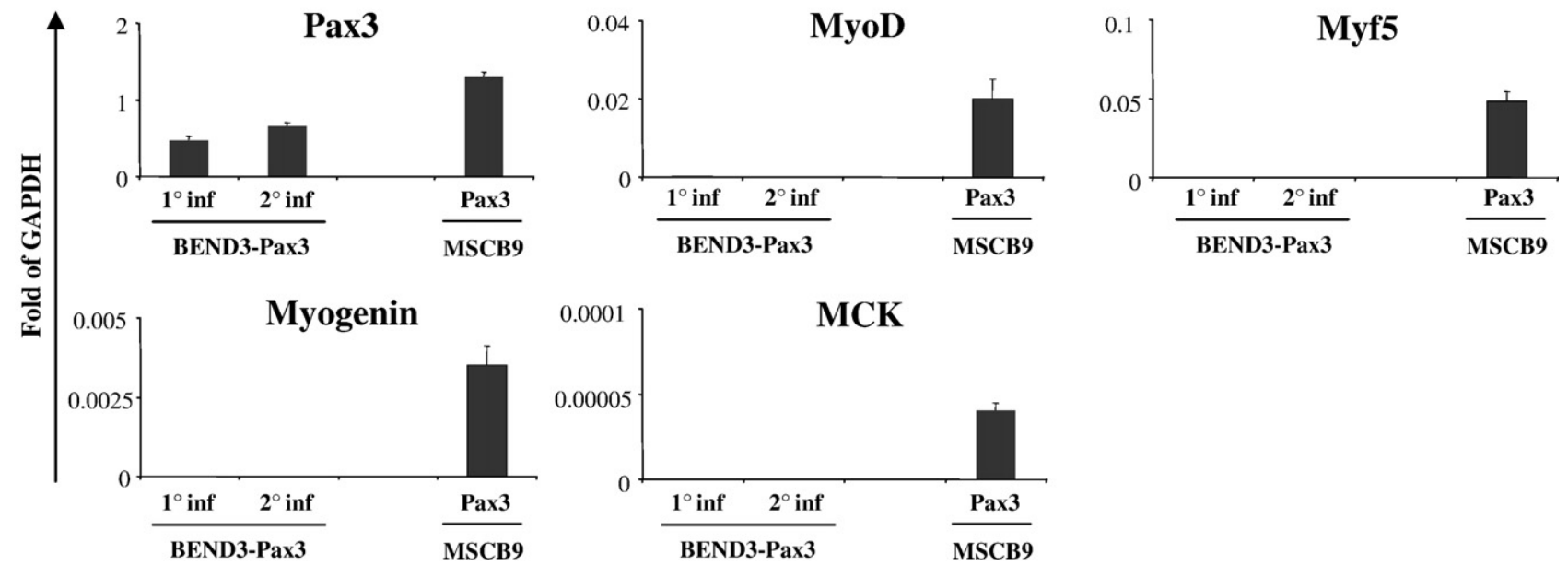

C
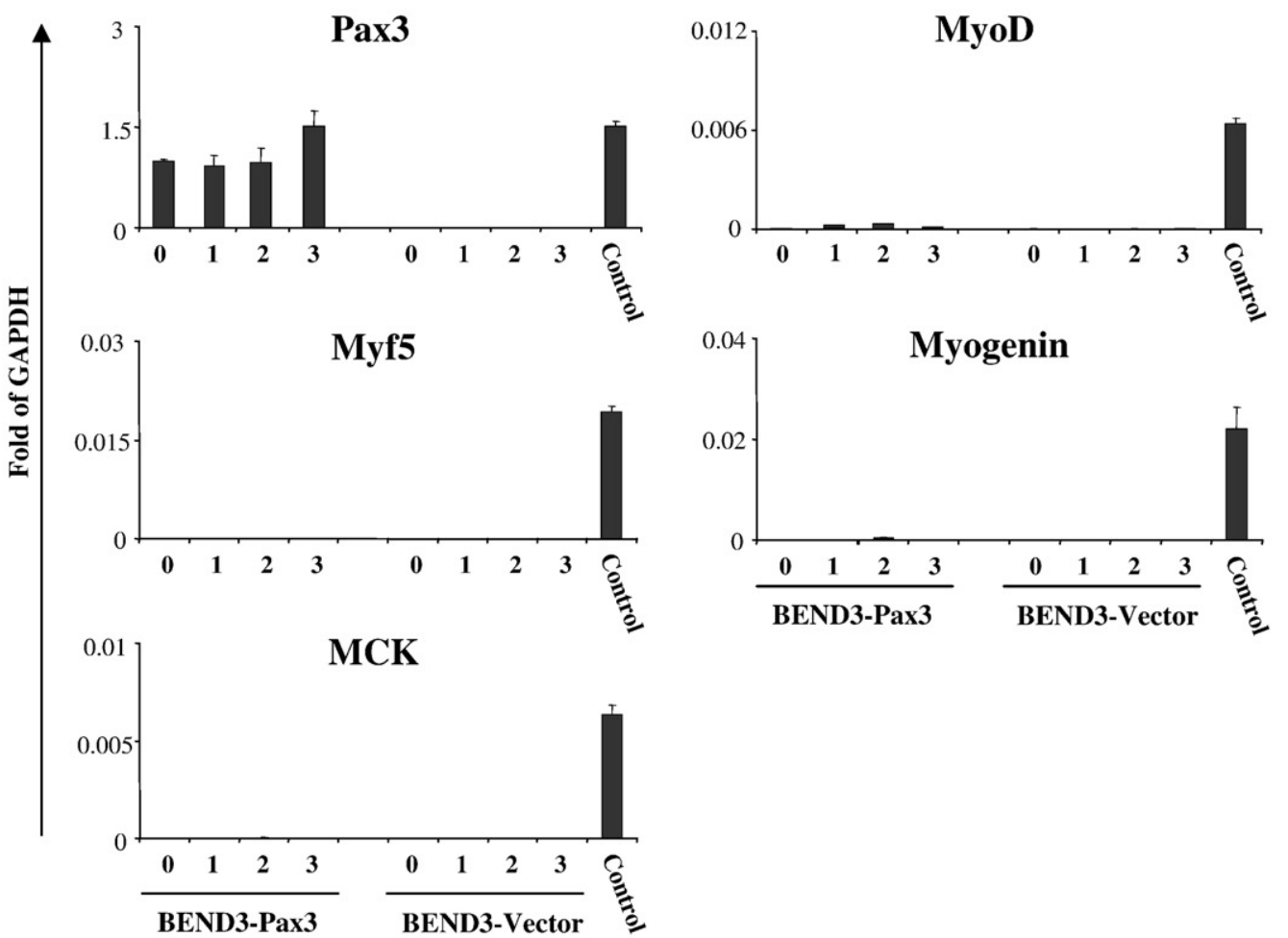


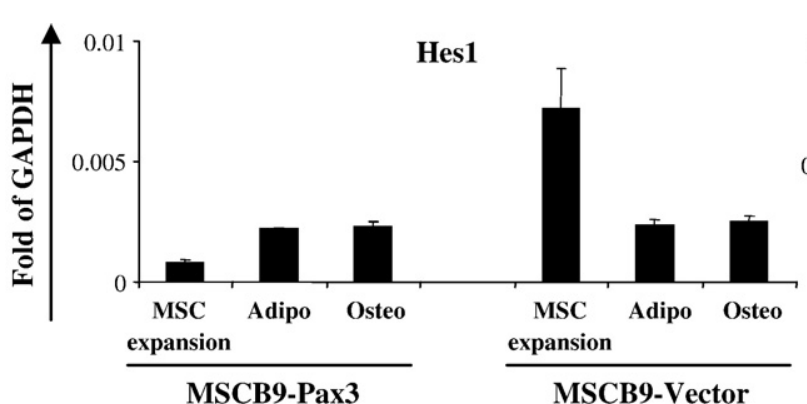

MSCB9-Pax 3
MSCB9-Vector

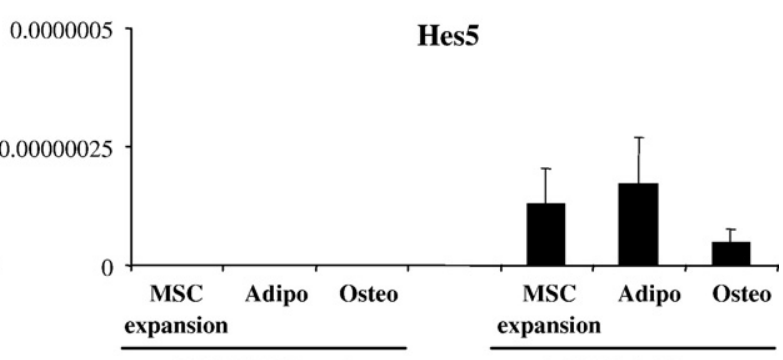

MSCB9-Pax3

MSCB9-Vector

Fig. 8 - Pax3 effects are independent of Notch. Real time PCR for Hes1 and Hes5 (downstream targets of Notch) in MSCB9-Pax3 and MSCB9-Vector cells growing under MSC expansion medium, adipogenic and osteogenic culture conditions. Transcripts are normalized to GAPDH. Error bars indicate standard deviations from two independent experiments performed in duplicate.

aggregated multinucleated myotubes were formed under these conditions (Fig. 6A.i). Myogenic markers including MyoD, Myf5, myogenin, and MCK were detected in MSCB9Pax3 but not in MSCB9-Vector cells (Fig. 6A.ii). No signal for these genes was detected in BEND3 cells, despite Pax3 overexpression (Fig. 6B.ii) in accordance with the lack of morphological changes (Fig. 6B.i). Since the levels of Pax3 were not as high in BEND3 cells as in MSCB9 and NIH 3T3 cells (Fig. 5D), we submitted BEND3-Pax3 cells with a second round of infection with Pax3. Regardless of higher expression of Pax3 (Fig. 7A), myogenic regulatory factors were still absent (Figs. 7B-C). These results indicate that Pax3 is not able to initiate the myogenic program in endothelial cells. On the other hand, expression of MRFs could be easily detected in NIH 3T3-Pax3 cells, in particular under condition 2 (Fig. 6C.ii). Although this induction did not result in significant morphological changes, MyoD could be detected at the protein level. This finding is not surprising since fibroblasts are the main cell type of stromal tissues, and belong to the mesenchymal compartment. Taken together, these results suggest that Pax3 promotes the muscle commitment only in specific cell types, in particular those of mesenchymal origin.

\section{Discussion}

During mouse embryogenesis, Pax3 is first expressed in the presomitic mesoderm. This expression is maintained in the somitic epithelium of the dermomyotome, and later on (10.5 d. p.c.) in the myotome [33,34]. Pax3 is also present in the brain, dorsally throughout the neural tube and in neural crest cells. Accordingly, Splotch (Pax3-null) mice die by E14.5 due to a number of developmental defects including impaired neural tube closure, defects in neural crest-derived structures, failure of cells within the dermomyotome to delaminate, and therefore, absence of limb muscles $[24,35,36]$. This later defect is associated with a lack of migratory muscle progenitors, which prevents MyoD activation by Myf5 and Mrf4 [20,28,36,37]. Because of this important role in muscle specification, Pax3 is considered a master regulator of the embryonic myogenic program [24,27].

Here we demonstrate that expression of Pax3 in a murine mesenchymal stem cell line enables the activation of the myogenic program in these cells. As observed during embryogenesis, Pax3 does so by activating downstream muscle-specific genes, including MyoD, Myf5 and myogenin. In the presence of muscle induction conditions, Pax3-MSC-derived myogenic progenitors undergo final maturation by differentiating into multinucleated myotubes (Figs. 3A-E). Previous work has demonstrated improved muscle differentiation of MSCs in the presence of Notch signaling [21]. Here the effect of Pax3 on muscle differentiation seems independent of the Notch pathway, as no up-regulation of Hes1 and Hes5, downstream targets of Notch, was observed (Fig. 8). Interestingly, activation of the myogenic program by Pax3 occurs at the expense of other mesenchymal lineages, as observed by its inhibitory effect on adipogenesis, osteogenesis, and chondrogenesis (Figs. 4A-B). Such transcriptional modulation has been previously described for mesenchymal lineages, in particular for fat and bone. For instance, it has been demonstrated that haploinsufficency of PPAR $\gamma-2$, a key transcription factor for adipogenesis, leads to osteogenesis by increased osteoblast formation [38,39]. Conversely, with aging, commitment of murine MSCs to the adipogenic lineage is enhanced at the expense of osteogenesis [40], a phenotype which correlates with increased levels of PPAR $\gamma$-2 [40]. While PPAR $\gamma-2$ is essential to drive adipogenesis from MSCs [38,43], Runx2 (Cbfa1) seems to be the key player for osteoblast differentiation [41-43]. Our results show that Pax3 overexpression blocks adipogenesis,

Fig. 7 - Expression of myogenic markers in BEND3-Pax3 cells subjected to 2 rounds of Pax3 infection. BEND3-Pax3 cells were re-infected with retrovirus prepared using MSCV-Pax3iresGFP. GFP ${ }^{+}$cells were sorted, as described in Fig. 4A.i, and cultured in MSC expansion medium (control, \#0). (A) Western blot analysis for Pax3, comparing 1 vs 2 round of Pax3 infection. (B) Gene expression analysis for myogenic markers in BEND3 Pax3 cells growing in MSC expansion medium. RNA was isolated from these cells one week post-sorting and analyzed for the expression of specific myogenic markers by real time RT-PCR, in which transcripts were normalized to GAPDH. (C) This gene expression profile remained the same even when cells were subjected to myogenic induction for 21 days. Real time RT-PCR analysis of respective cells cultured under several muscle induction conditions, as follows: \#1, LG-DMEM supplemented with 10\% FBS; \#2, MSC expansion medium containing no growth factors; \#3, LG-DMEM supplemented with $2 \%$ HS. Error bars in (B) and (C) indicate standard deviations from two independent experiments performed in duplicate. cDNA from MSCB9-Pax3 cells were used as positive control. 
osteogenesis, and chondrogenesis potentially by inhibiting PPAR $\gamma-2$ and Cbfa- 1 .

Importantly, Pax3 enables muscle commitment specifically in MSCs. Despite Pax3 overexpression, endothelial cells fail to activate the myogenic program. Although Pax3 expression in fibroblasts results in activation of MRFs, this is not accompanied by morphological changes typical of myogenic progenitors or myotubes (Fig. 6C). Our results show that under Pax3 activation only MSCs give rise to myogenic progenitors capable of undergoing final maturation in vitro. This cell typeselective effect of Pax3 is also observed during embryogenesis, since despite being expressed in the neural tube, Pax3 does not cause myogenesis to occur at this site.

Taken together, our data reveal the potential of regulating transcriptional pathways to direct differentiation of adult stem cells.

\section{Acknowledgments}

This work was supported by the Dr. Bob and Jean Smith Foundation. The monoclonal antibody to MHC was obtained from the Developmental Studies Hybridoma Bank developed under the auspices of the NICHD and maintained by the University of Iowa.

\section{REFERENCES}

[1] G. Ferrari, G. Cusella-De Angelis, M. Coletta, E. Paolucci, A. Stornaiuolo, G. Cossu, F. Mavilio, Muscle regeneration by bone marrow-derived myogenic progenitors, Science 279 (1998) 1528-1530.

[2] E. Gussoni, Y. Soneoka, C.D. Strickland, E.A. Buzney, M.K. Khan, A.F. Flint, L.M. Kunkel, R.C. Mulligan, Dystrophin expression in the mdx mouse restored by stem cell transplantation, Nature 401 (1999) 390-394.

[3] R.E. Bittner, C. Schofer, K. Weipoltshammer, S. Ivanova, B. Streubel, E. Hauser, M. Freilinger, H. Hoger, A. Elbe-Burger, F. Wachtler, Recruitment of bone-marrow-derived cells by skeletal and cardiac muscle in adult dystrophic mdx mice, Anat. Embryol. (Berl). 199 (1999) 391-396.

[4] S. Fukada, Y. Miyagoe-Suzuki, H. Tsukihara, K. Yuasa, S. Higuchi, S. Ono, K. Tsujikawa, S. Takeda, H. Yamamoto, Muscle regeneration by reconstitution with bone marrow or fetal liver cells from green fluorescent protein-gene transgenic mice, J. Cell Sci. 115 (2002) 1285-1293.

[5] M. Abedi, D.A. Greer, B.M. Foster, G.A. Colvin, J.A. Harpel, D.A. Demers, J. Pimentel, M.S. Dooner, P.J. Quesenberry, Critical variables in the conversion of marrow cells to skeletal muscle, Blood 106 (2005) 1488-1494.

[6] P. Bossolasco, S. Corti, S. Strazzer, C. Borsotti, R. Del Bo, F. Fortunato, S. Salani, N. Quirici, F. Bertolini, A. Gobbi, G.L. Deliliers, G. Pietro Comi, D. Soligo, Skeletal muscle differentiation potential of human adult bone marrow cells, Exp. Cell Res. 295 (2004) 66-78.

[7] G. Ferrari, A. Stornaiuolo, F. Mavilio, Failure to correct murine muscular dystrophy, Nature 411 (2001) 1014-1015.

[8] R.F. Pereira, K.W. Halford, M.D. O'Hara, D.B. Leeper, B.P. Sokolov, M.D. Pollard, O. Bagasra, D.J. Prockop, Cultured adherent cells from marrow can serve as long-lasting precursor cells for bone, cartilage, and lung in irradiated mice, Proc. Natl. Acad. Sci. U. S. A. 92 (1995) 4857-4861.

[9] D.J. Prockop, Marrow stromal cells as stem cells for nonhematopoietic tissues, Science 276 (1997) 71-74.
[10] M.F. Pittenger, A.M. Mackay, S.C. Beck, R.K. Jaiswal, R. Douglas, J.D. Mosca, M.A. Moorman, D.W. Simonetti, S. Craig, D.R. Marshak, Multilineage potential of adult human mesenchymal stem cells, Science 284 (1999) 143-147.

[11] S. Wakitani, T. Saito, A.I. Caplan, Myogenic cells derived from rat bone marrow mesenchymal stem cells exposed to 5-azacytidine, Muscle Nerve 18 (1995) 1417-1426.

[12] S.F. Konieczny, C.P.J. Emerson, 5-Azacytidine induction of stable mesodermal stem cell lineages from 10T1/2 cells: evidence for regulatory genes controlling determination, Cell 38 (1984) 791-800.

[13] A.B. Lassar, B.M. Paterson, H. Weintraub, Transfection of a DNA locus that mediates the conversion of 10T1/2 fibroblasts to myoblasts, Cell 47 (1986) 649-656.

[14] M. Shiota, T. Heike, M. Haruyama, S. Baba, A. Tsuchiya, H. Fujino, H. Kobayashi, T. Kato, K. Umeda, M. Yoshimoto, T. Nakahata, Isolation and characterization of bone marrow-derived mesenchymal progenitor cells with myogenic and neuronal properties, Exp. Cell Res. 313 (2007) 1008-1023.

[15] J. Chan, K. O’Donoghue, M. Gavina, Y. Torrente, N. Kennea, H. Mehmet, H. Stewart, D.J. Watt, J.E. Morgan, N.M. Fisk, Galectin-1 induces skeletal muscle differentiation in human fetal mesenchymal stem cells and increases muscle regeneration, Stem Cells 24 (2006) 1879-1891.

[16] T. Saito, J.E. Dennis, D.P. Lennon, R.G. Young, A.I. Caplan, Myogenic expression of mesenchymal stem cells within myotubes of $\mathrm{mdx}$ mice in vitro and in vivo, Tissue Eng. 1 (1995) 327-343.

[17] K. Goldring, G.E. Jones, R. Thiagarajah, D.J. Watt, The effect of galectin-1 on the differentiation of fibroblasts and myoblasts in vitro, J. Cell Sci. 115 (2002) 355-366.

[18] F. Relaix, D. Rocancourt, A. Mansouri, M. Buckingham, A Pax3/Pax7-dependent population of skeletal muscle progenitor cells, Nature 435 (2005) 948-953.

[19] L. Kassar-Duchossoy, E. Giacone, B. Gayraud-Morel, A. Jory, D. Gomes, S. Tajbakhsh, Pax3/Pax7 mark a novel population of primitive myogenic cells during development, Genes Dev. 19 (2005) 1426-1431.

[20] L. Kassar-Duchossoy, B. Gayraud-Morel, D. Gomes, D. Rocancourt, M. Buckingham, V. Shinin, S. Tajbakhsh, Mrf4 determines skeletal muscle identity in Myf5:MyoD double-mutant mice, Nature 431 (2004) 466-471.

[21] M. Dezawa, H. Ishikawa, Y. Itokazu, T. Yoshihara, M. Hoshino, S. Takeda, C. Ide, Y. Nabeshima, Bone marrow stromal cells generate muscle cells and repair muscle degeneration, Science 309 (2005) 314-317.

[22] B. Christ, C.P. Ordahl, Early stages of chick somite development, Anat. Embryol. (Berl). 191 (1995) 381-396.

[23] P. Bailey, T. Holowacz, A.B. Lassar, The origin of skeletal muscle stem cells in the embryo and the adult, Curr. Opin. Cell Biol. 13 (2001) 679-689.

[24] M. Goulding, A. Lumsden, A.J. Paquette, Regulation of Pax-3 expression in the dermomyotome and its role in muscle development, Development 120 (1994) 957-971.

[25] W.F.J. Denetclaw, B. Christ, C.P. Ordahl, Location and growth of epaxial myotome precursor cells, Development 124 (1997) 1601-1610.

[26] C.P. Ordahl, N.M. Le Douarin, Two myogenic lineages within the developing somite, Development 114 (1992) 339-353.

[27] J.P. Tremblay, S. Dietrich, M. Mericskay, F.R. Scubert, Z. Li, D. Paulin, A crucial role for Pax3 in the development of the hypaxial musculature and the long-range migration of muscle precursors, Dev. Biol. 203 (1998) 49-61.

[28] M. Maroto, R. Reshef, A.E. Munsterberg, S. Koester, M. Goulding, A.B. Lassar, Ectopic Pax-3 activates MyoD and Myf-5 expression in embryonic mesoderm and neural tissue, Cell. 89 (1997) 139-148. 
[29] L. Bajard, F. Relaix, M. Lagha, D. Rocancourt, P. Daubas, M.E. Buckingham, A novel genetic hierarchy functions during hypaxial myogenesis: Pax3 directly activates Myf5 in muscle progenitor cells in the limb, Genes Dev. 20 (2006) 2450-2464.

[30] F. Relaix, D. Rocancourt, A. Mansouri, M. Buckingham, Pax3/Pax7 mark a novel population of primitive myogenic cells during development, Genes Dev. 18 (2004) 1088-1105.

[31] E.J. Gang, D. Bosnakovski, C.A. Figueiredo, J.W. Visser, R.C. Perlingeiro, SSEA-4 identifies mesenchymal stem cells from bone marrow, Blood 109 (2007) 1743-1751.

[32] D. Yaffe, O. Saxel, Serial passaging and differentiation of myogenic cells isolated from dystrophic mouse muscle, Nature 270 (1977) 725-727.

[33] F.R. Schubert, P. Tremblay, A. Mansouri, A.M. Faisst, B. Kammandel, A. Lumsden, P. Gruss, S. Dietrich, Early mesodermal phenotypes in splotch suggest a role for Pax3 in the formation of epithelial somites, Dev. Dyn. 222 (2001) 506-521.

[34] B.A. Williams, C.P. Ordahl, Pax-3 expression in segmental mesoderm marks early stages in myogenic cell specification, Development 120 (1994) 785-796.

[35] D.J. Epstein, M. Vekemans, P. Gros, Splotch (Sp2H), a mutation affecting development of the mouse neural tube, shows a deletion within the paired homeodomain of Pax-3, Cell 67 (1991) 767-774.

[36] E. Bober, T. Franz, H.H. Arnold, P. Gruss, P. Tremblay, Pax-3 is required for the development of limb muscles: a possible role for the migration of dermomyotomal muscle progenitor cells, Development 120 (1994) 603-612.
[37] S. Tajbakhsh, D. Rocancourt, G. Cossu, M. Buckingham, Redefining the genetic hierarchies controlling skeletal myogenesis: Pax3 and Myf-5 act upstream of MyoD, Cell 89 (1997) 127-138.

[38] T. Akune, S. Ohba, S. Kamekura, M. Yamaguchi, U.I. Chung, N. Kubota, Y. Terauchi, Y. Harada, Y. Azuma, K. Nakamura, T. Kadowaki, H. Kawaguchi, PPARgamma insufficiency enhances osteogenesis through osteoblast formation from bone marrow progenitors, J. Clin. Invest. 113 (2004) 846-855.

[39] L. Pei, P. Tontonoz, Fat's loss is bone's gain, J. Clin. Invest. 113 (2004) 805-806.

[40] E.J. Moerman, K. Teng, D.A. Lipschitz, B. Lecka-Czernik, Aging activates adipogenic and suppresses osteogenic programs in mesenchymal marrow stroma/stem cells: the role of PPAR-gamma2 transcription factor and TGF-beta/BMP signaling pathways, Aging Cell 3 (2004) 379-389.

[41] P. Ducy, R. Zhang, V. Geoffroy, A.L. Ridall, G. Karsenty, Osf2/Cbfa1: a transcriptional activator of osteoblast differentiation, Cell 89 (1997) 747-754.

[42] T. Komori, H. Yagi, S. Nomura, A. Yamaguchi, K. Sasaki, K. Deguchi, Y. Shimizu, R.T. Bronson, Y.H. Gao, M. Inada, M. Sato, R. Okamoto, Y. Kitamura, S. Yoshiki, T. Kishimoto, Targeted disruption of Cbfa1 results in a complete lack of bone formation owing to maturational arrest of osteoblasts, Cell 89 (1997) 755-764.

[43] J.H. Hong, E.S. Hwang, M.T. McManus, A. Amsterdam, Y. Tian, R. Kalmukova, E. Mueller, T. Benjamin, B.M. Spiegelman, P.A. Sharp, N. Hopkins, M.B. Yaffe, TAZ a transcriptional modulator of mesenchymal stem cell differentiation, Science. 309 (2005) 1074-1078. 